\title{
Father Involvements Influence on Mother's Perceptions of Parenting in an Appalachian Sample
}

\author{
Kalynn B. Amick
}

Follow this and additional works at: https://researchrepository.wvu.edu/etd

\section{Recommended Citation}

Amick, Kalynn B., "Father Involvements Influence on Mother's Perceptions of Parenting in an Appalachian Sample" (2015). Graduate Theses, Dissertations, and Problem Reports. 5095.

https://researchrepository.wvu.edu/etd/5095

This Thesis is protected by copyright and/or related rights. It has been brought to you by the The Research Repository @ WVU with permission from the rights-holder(s). You are free to use this Thesis in any way that is permitted by the copyright and related rights legislation that applies to your use. For other uses you must obtain permission from the rights-holder(s) directly, unless additional rights are indicated by a Creative Commons license in the record and/ or on the work itself. This Thesis has been accepted for inclusion in WVU Graduate Theses, Dissertations, and Problem Reports collection by an authorized administrator of The Research Repository @ WVU. For more information, please contact researchrepository@mail.wvu.edu. 
Father Involvements Influence on Mother's Perceptions of Parenting in an Appalachian Sample

\author{
Kalynn B. Amick
}

\begin{abstract}
Thesis submitted to the
College of Education and Human Services

At West Virginia University

In partial fulfillment of the requirements for the degree of
\end{abstract}

\author{
Master of Arts \\ In \\ Educational Psychology \\ with an emphasis in Child Development and Family Studies
}

Jessica Troilo, Ph.D., Chairperson

Amy Root, Ph.D.

Audra Slocum, Ph.D.

Department of Learning, Sciences, and Human Development

Morgantown, West Virginia

2015

Keywords: Appalachia, father involvement, mothering perceptions, parenting, low-income Copyright 2015 Kalynn B. Amick 


\section{ABSTRACT \\ Father Involvements Influence on Mother's Perceptions of Parenting in an Appalachian Sample}

\section{by Kalynn Amick}

Father involvement in parenting can have a positive influence on both children and mothers. During times of economic stress it may also add to the resources available and make a positive contribution to mothers parenting practices. In this study it was considered how father involvement may influence mother's perceptions of parenting. Specifically, this study looks at father involvement in an Appalachian sample. Five participants completed questionnaires which answered questions about mothers' present perceptions of parenting and father involvement. No significant associations were found between father involvement and mother's perceptions of parenting. Limitations include small sample size and a lack of diversity in the sample. Possibilities for future research include cultural inclusion and qualitative questionnaires as well. Limitations and additional possibilities for future research are discussed in greater detail within the study. 


\section{Table of Contents}

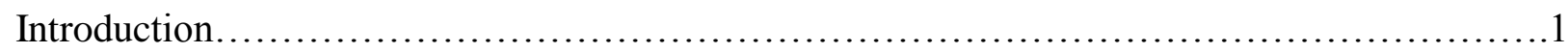

Justification for the Study...............................................

Review of Literature .............................................................

Parenting in Low Income, Rural Families....................................5

Father's Role in Parenting....................................................... 8

Father's Contribution to Low Income Mother's Parenting..........................13

Current Study.............................................................. 17

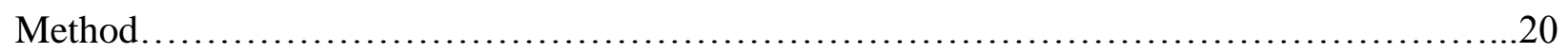

Participants............................................................20

Procedure................................................................20

Questionnaires.........................................................21

Data Analysis..........................................................23

Results..................................................................... 24

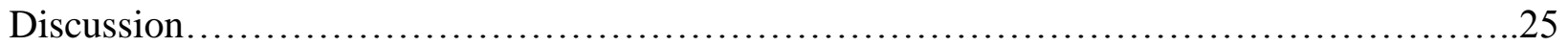

Limitations and Future Research.........................................25

Conclusions.......................................................... 26

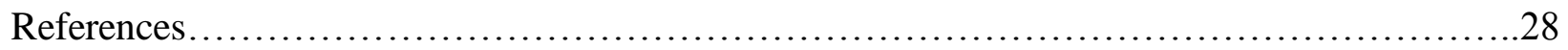




\section{List of Appendices}

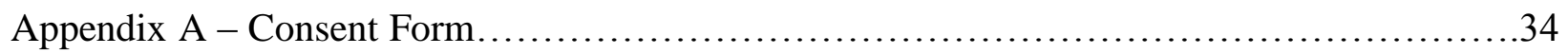

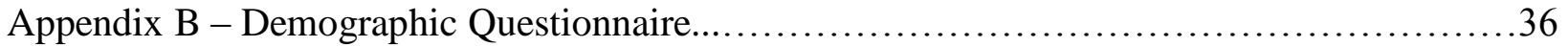

Appendix C - Parenting Questionnaire - Retrospective ...............................39

Appendix D - Parenting Questionnaire - Current...................................40

Appendix E - Current Father Involvement Questionnaire..............................41 


\section{Chapter I}

\section{Introduction}

Father absence is more prevalent in families from communities that are considered to be disadvantaged (i.e. low income, high teen pregnancy rate, etc.) than it is in families from more advantaged communities throughout the United States (Harper \& McLanahan, 2004). The US Census Bureau website gives an average number of families living in poverty in West Virginia for at least a 12 month span between 2009 and 2013. The average numbers varied depending on type of household (i.e., married couple, male headed, female headed). There was an average of 14,365 married couples with children under the age of 18 living in poverty, 5,048 male headed households (no wife present) with children under the age of 18 living in poverty, and 25,736 female headed households (no husband present) with children under the age of 18 living in poverty (US Census, 2014). Because of the high prevalence of Appalachian communities and families experiencing the devastating effects of poverty (Newsome, Bush, Hennon, Peterson, \& Wilson, 2008), there is, in turn, a potential of absent fathers. Father absence can then exacerbate stress from economic pressures and child care, which creates a less than ideal environment for child development and child outcomes. There has been research that indicates father absence may act as a protective factor for children and mothers. In some of these cases, fathers have been reported to be abusive and therefore pose a risk for children and mothers (Downs \& Rindels, 2004; Juby, Downs, \& Rindels, 2014). With this in mind, it is not the intention of the study to relay father absence as conclusively negative; however, in light of research done with similar populations to the current study's, this study will consider father absence a risk factor for children and mother's child-rearing practices. 
When families experience hard economic times, children are impacted indirectly through their parents' reactions to the stress (Conger \& Conger, 2008). Experiencing emotional distress may lead parents to display less warmth and become less engaged with their children (Conger \& Conger, 2008). The Family Adjustment and Adaptation Response (FAAR) Model suggests that families strive to maintain balance in the face of economic stress. It is a process of balancing demands and resources. When the demands out-weigh the resources, a crisis occurs and the family attempts to adapt (Patterson, 1988). When the family cannot adapt, negative outcomes occur for both parent(s) and child.

In West Virginia there are more than double the amount of single parent households living in poverty than there are two parent households (US Census, 2014). It has been found that father absence from the family can have a negative effect on child outcomes, especially in a lowincome context because of indirect effects through the loss of income for the family and increased workload and stress on the mother (Harper \& McLanahan, 2004). When the mother's parenting duties take on a more intensive and time consuming role than expected this can have negative effects on the mother's well-being as well (Biehl \& Mickelson, 2012; Goldberg \& Perry-Jenkins, 2004). However, when father's and mother's expectations of father involvement fall in line with one another, there is less stress within the relationship.

Even though these expectations may or may not include involving the father in the child's life, research with diverse samples (i.e. varying SES) has found that an involved father can act as a protective factor when a child is exposed to an adverse environment. Children have more positive education outcomes (e.g., higher IQ) and fewer behavioral problems (e.g., skipping school, substance consumptions, illegal activities, etc.) (Cabrera, Tamis-LeMonda, Bradley, Hofferth, \& Lamb, 2000; Flouri \& Buchanan, 2004; Nettle, 2008). A father can take an active, 
physical role in his child's life (Fagan \& Palkovitz, 2011) and actively takes care of his child, teaches his child and engages in activities with his child (Pleck, 2010). One way this involvement acts as a protective factor is through play. When the father is actively engaging in play with his son or daughter during the child's preschool years, he teaches his child emotion regulation and how to read and send emotion cues to other individuals (Parke, 1996). Father play is more physical and rigorous than maternal play and during this play with the father the child must communicate with his or her father about the appropriate level of play that each member is comfortable with (Parke, 1996).

There are ways in which a father influences his child directly (such as through play), and indirect ways as well. Choi (2010) argues that fathers have a much larger indirect effect on child development through his influence on mother's parenting practices. This influence can be seen through his economic contribution. This allows the financial resources available to the family to increase and makes providing food and other necessities much easier and lessens the stress on the mother. More than just financial contribution, father involvement as defined by Pleck (2010) also influences the mother's parenting practices as well as directly influencing the child. The degree to the involvement and the influential power of this involvement in Appalachia has not been readily studied. Therefore, in this study the aim is to determine the significance of the influence of father involvement on mother's perceptions of parenting from a rural, low-income West Virginia sample.

\section{Justification for the Study}

Little research has been done in the field of Appalachian parenting. Some researchers have argued that Appalachia provides separate cultural context and therefore a unique case in research (Horning, 2002; Newsome et al., 2008), but others would argue that despite a few 
unique characteristics Appalachia should not be considered a culturally separate entity of the U.S. (Batteau, 1979; Billings, Blee, \& Swanson, 1986). It is, of course, important to understand a culture when implementing interventions or directly interacting with a population and so the characteristics of Appalachia should be appreciated and understood. However, for the purposes of this study the focus will be put on the low-income, rural aspect of this Appalachian population.

This study will use a sample from low-income West Virginia and as it has been found in previous research, a low-income environment acts as a threat to the family unit through stress (Conger \& Conger, 2008). In addition to stressors within the family unit, in some low-income, rural areas resources are scarce. Gorski (2013) argues that low-income students succeed less than their wealthier counterparts not because of an apathy or learned deficit associated with poverty, but because of a lack of access to the educational resources provided to their peers living in wealthier communities. For example, one in four classrooms in high-poverty schools are taught by unqualified teachers, while one in nine classrooms in low-poverty schools are taught by unqualified teachers. In the same way, access to high-quality preschools, if a family can even afford preschool, or after school programs that could keep children out of trouble is missing for a lot of low-income families living in a high-poverty community (Gorski, 2013). Even though Gorski (2013) is speaking about education specifically, it is apparent that the resources available to families living in poverty are not the same as their wealthier counterparts. Considering the low-income environment of this rural West Virginia sample as a part of Appalachia and the lack of resources in a lot of low-income rural areas, this study will help shed light on the importance of understanding and providing help to Appalachian fathers and mothers to increase the effectiveness of parenting practices and provide a positive nurturing community to the children of this area. These findings will hopefully provide local practitioners (e.g. 
teachers, counselors, social workers, etc.) with useful information that can be used when providing support to parents of this region and provide a deeper understanding of the father's place within the parental dyad. 


\section{Chapter II}

\section{Review of Literature}

\section{Parenting in Low Income, Rural Families}

Families in poverty often experience hardships that include trouble paying bills, providing food for their children, or providing suitable toys and other learning materials to help facilitate appropriate development for their children. These hardships can have serious, negative physical and cognitive consequences on children's development. Research has also shown that parents living in poverty experience more stress than parents with higher incomes, and this increased stress impacts their parenting practices in potentially harmful ways (Bachman, Coley \& Carrano, 2012; Brody et al., 1994; Magnuson \& Duncan, 2005). As parent economic stress increases, parents can experience emotional distress that can then decrease the parents' responsiveness to his or her children and may influence negative interactions with children (Conger \& Conger, 2008). In light of these findings, family stress theory will be used to understand how low-income Appalachian mother's perceptions of parenting may be influenced by economic stressors and how father's involvement in parenting may act as a mediator between the mother's perceptions and economic stress.

As family stress theory pertains specifically to parenting consequences, Conger and Conger (2008) state that stress felt by parents in times of economic hardship will negatively affect their mood and actions towards their children and this influences their parenting practices. As stress increases, a parent experiences an increased amount of emotional distress that can result in depression, anxiety, or other mental health issues (Conger \& Conger, 2008). These can result in withdrawal from their relationships with their children or even decreased warmth 
towards their children as well as increased relational stress and conflict within the co-parent's relationship (i.e. the parents who work together to raise their children).

The family stress theory suggests that how parents deal with hard economic times is related to child adjustment. Children are indirectly affected by the harsh economic conditions through their parents' experiences (Conger \& Conger, 2008; Conger et al., 1992). Therefore, as parents react with emotional distress and conflict, children will experience negative adjustment (i.e., social competence, cognitive abilities), internalizing (anxiety, depression, etc.) and externalizing (aggression, substance abuse, etc.) behaviors while living in harsh economic conditions (Conger \& Conger, 2008).

Conger and colleagues have done multiple research studies using samples from the rural Midwest that have supported the family stress model (Conger \& Conger, 2002; Conger et al., 1992, 1993). The samples come from a cohort of Midwestern $7^{\text {th }}$ graders living in two parent households with a sibling within 4 years of the $7^{\text {th }}$ grader. In the late 1980 's there was an agricultural crisis that resulted in a downturn in the rural, Midwestern economy and a longitudinal study was conducted with the cohort that experienced this economic change (Conger \& Conger, 2002; Conger et al., 1992, 1993). The sample was diversified in 1991 with the addition of $9^{\text {th }}$ graders and their families with close siblings and is headed by a single-mother (Conger \& Conger, 2002). Conger and his colleagues found in their analysis of the data from these cohorts in the Iowa Youth and Families Project (IYFP) that which the family stress model proposes: children who have parents that deal with economic hardships more positively (e.g., minimal emotional distress, little inter-parental conflict, and maintain nurturing parenting skills) have more positive adjustment outcomes than children who have parents that experience negative outcomes from economic hardships (Conger \& Conger, 2002; Conger et al., 1992, 
1993). This rural Midwestern sample provides an emphasis on the need to provide a positive, nurturing parenting environment in the face of economic hardships when families would have a difficult time providing basic needs and paying bills which will increase stress.

Although this sample came from the Midwest, it focuses on a rural, low-income subsection of the population. Economic hardship introduces stress to families without discrimination. So, taking into account the findings from the Midwest, this can help to understand the current study's rural, low-income Appalachian sample and it's response to economic hardships. In addition, this study will also consider the involvement of the father in reducing parenting stress. As discussed next, father involvement will act as a resource to maintain normal, positive functioning in the presence of stress caused by economic hardships.

The Family Adjustment and Adaptation Response (FAAR) Model of family stress theory allows a theoretical explanation for the Conger et al. $(1992,1993)$ findings and the anticipated findings of this study. The FAAR model suggests that as the family unit goes through a crisis it strives to maintain its normal family functioning processes. The family unit will attempt to maintain normal functioning by battling demands (i.e. stressors) with capabilities (i.e. resources). There are two phases in which this occurs: the adjustment phase and the adaptation phase. The adjustment phase occurs when minor changes are implemented within the family unit in order to use the resources available to the family for them to deal with the demands that are being made. When the demands exceed the resources available to the family, a family crisis emerges and the adaptation phase starts. During the adaptation phase the family attempts to restore balance to the family unit by finding new capabilities, letting go of some demands or by changing their mind set as it pertains to the family unit's crisis (Patterson, 1988). The purpose of this study is to explore the idea that the father is able to help the family adjust or adapt in times of stress, 
specifically economic stress, and positively influences mother's parenting. In order to explore this idea, fathers' roles in parenting must first be understood.

\section{Father's Role in Parenting}

Traditionally, mothers acted as children's primary caregiver while fathers were the primary breadwinners for the family (Cabrera et al., 2000; Paquette, 2004). In recent years, this has changed as mothers have increasingly become a part of the work force and the prevalence of single parent homes has increased (Cabrera et al., 2000). According to the U.S. Census Bureau in 2011 there were over 24 million children living apart from their biological fathers; $44 \%$ of those children living with only their mothers lived in poverty. In West Virginia, about $11 \%$ of households are absent father households (the percentages for urban and rural father absent household are about the same; US Census, 2010), but when considering the impoverished population of West Virginia 57\% of families living in poverty with children under the age of 18 are absent father households (US Census, 2014). Although some fathers have become more involved in taking care of their children, absent fathers have become an increasing concern, in part, because of the potential impact on the development of their children (Harper \& McLanahan, 2004; Mendle et al., 2009; Pougnet, Serbin, Stack, Ledingham, \& Schwartzman, 2012). A study done with a low SES, urban sample in Quebec, Canada has found that male children with absent fathers are more likely than their peers with present fathers to be absent fathers themselves, while female children with absent fathers are more likely to have children with a partner who is absent (Pougnet et al., 2012). These findings show an intergenerational effect of father absence, but it is unclear if this may be a genetic effect, environmental (e.g. community) effect, or a learned behavior. However, the researchers do believe that children will play out the relationship roles 
they see their parents taking part in (Pougnet et al., 2012). Therefore, the quality of the parental relationship or even its existence will influence a child well into their adult years.

Because of this cyclical generational influence father absence has on children, there is the possibility that the number of children experiencing life with an absent father will increase, which in turn will increase the number of children experiencing negative developmental outcomes because of their family situation and environment. Previous research done on a crossnational sample has found that when a father is completely absent from a child's life, negative outcomes may accompany this. Mendle et al. (2009) found that children with absent fathers have their first sexual intercourse at an earlier age than their peers with non-absent fathers. However, the authors also found that there may be an environmental factor that comes into play, so it is a combination of the child's environment (e.g. poverty, violence, lack of resources) and an absent father that leads to an earlier first sexual intercourse (Mendle et al., 2009).

Just as Mendle and colleagues (2009) discuss a specific result of father absence as being early first sexual experience, other researchers have found additional behavioral consequences of father absence. DeBell (2008) argues that traditional gender roles makes the father the disciplinarian, therefore the absence of the father leads to more instances of suspension and expulsion from school, but other factors remain successfully developing as long as children are not disadvantaged in other areas (e.g. SES). Because of the sample that will be studied (economically disadvantaged Appalachia), it is safe to assume negative outcomes in the event of father absence in this disadvantaged group despite DeBell's (2008) findings from his economically diverse, cross-national sample. Similar findings come from research done by Harper and McLanahan (2004) on a sample that was also economically diverse and crossnational. Incarceration rates were higher for adolescents with absent fathers; however, the 
authors argue that the high rate of incarceration is a result of the disadvantage that is a result of an absent father. Father absence is more prevalent in areas with a high rate of teen pregnancy, low education and low SES. The authors found that poverty and father departure during childhood or before birth were connected with high rates of incarceration (Harper \& McLanahan, 2004). This is a concerning thought for low-income areas in Appalachia, and one of the reasons it is important to understand the risk factors in living with an absent father.

Concerning the current study's low-income sample, having an absent father is likely a risk factor for these families. However, it cannot be assumed that the mere presence of a father will be a protective factor against the outcomes discussed above, especially in a disadvantaged setting. Both men and women have their own views on what it is to be a committed father who is maintaining the paternal role in an appropriate manner. There are some men who believe that being financially responsible shows their commitment regardless of their presence in the child's life, while other fathers take on a more involved role in their children's lives (Bryan, 2013). Using data from the National Longitudinal Survey of Youth, Parke (1996) found that Caucasian males whose fathers were not present had significantly more trouble with peers, higher rates of disobedient behaviors and felt more negatively than their counterparts who had present fathers. Caucasian females without a father present had high rates of cheating and lying compared to Caucasian females with a father present. Interestingly, African American males and females with absent fathers did not show the same adverse behaviors as their Caucasian counterparts (Parke, 1996). A possible explanation for these findings is that Caucasian fathers tend to leave their children during early childhood whereas African American fathers are likely to have been absent from the home the child's whole life (Parke, 1996). Therefore Caucasian children have 
had to transition into life without a father and learn to emotionally handle the loss of his or her father.

These findings reflect the adverse effects of a father not being present in a child's life, but some studies have found the quality of the father involvement in a child's life is more influential in a child's development than the amount of time spent with the child (Cabrera et al., 2000; Choi, 2010; Paquette, 2004). For example, it has been found that positive father involvement in middle childhood leads to positive educational outcomes and acts as a protective factor to delinquent behaviors (i.e. drug or alcohol consumption, skipping school, participation in illegal activities, etc.) in adolescence (Cabrera et al., 2000). Research has also found that children with involved fathers have higher IQ's (Flouri \& Buchanan, 2004; Nettle, 2008). In order to understand why involvement may be so significant in a child's development, we must understand what constitutes an involved father and why this is different than mere presence.

Fagan and Palkovitz (2011) define an involved father as one who takes part in observable, physical interactions with his child. Pleck (2010) breaks down father involvement even further into three main components. He argues that father involvement is made up of positive engagement activities, warmth and responsiveness, and control. He also includes two auxiliary components (indirect care and process responsibility) in his involvement practices breakdown. The fathering actions that make up these components of father involvement are what differentiate involvement from mere presence in the child's life. Where father presence is merely the father being physically present in their child's life (either living in the same home or having occasional visits) with little meaningful or impactful interactions, involvement is when a father plays an active role in taking care of the child, teaching the child, and engaging the child. 
Pleck's (2010) components of father involvement gives specific ways in which the father actively participates in the child's life. Positive engagement includes actions that allow the father and child to interact in a positive and meaningful way that will promote bonding between the two (i.e. board games, reading books together, playing outdoors, etc.). The second component is warmth and responsiveness. This component includes communication (both verbal and nonverbal) in which father and child express feelings in a presumably positive manner (i.e. hugging, kissing, saying "I love you", telling the child he or she is appreciated, etc.). The last main component of father involvement as defined by Pleck (2010) is control. This component is made up of actions or decisions that set up boundaries for the child based on the father's desires for the child's life (i.e. limiting how much TV and what kind of TV the child watches, who the child's playmates are, etc.). The two auxiliary components that Pleck (2010) presents as part of father involvement are indirect care, which entails actions that are undertaken for the child without interacting with the child (i.e. selecting child care), and process responsibility, which is when fathers take over primary care of the child.

As related to the positive engagement component of involvement, studies have found that involved fathers who engage in play with their children have an important role in the positive development of emotion regulation and better peer relations in their children (Paquette, 2004). Father - child play is characterized by more physically rigorous and explorative play than mother - child play. Mothers are more apt to revolve play around a play object; fathers are more likely to engage in physical play (Parke, 1996). It has been found that children with fathers who participate in longer physical and less directive play are more popular with their peers (McDowell \& Park, 2009; Parke \& O’Neil, 2000). This may be because during this play time fathers provide their children with a warm but controlled environment to take risks and 
make/comply to play decisions. The child learns how to read emotion cues and send effective emotion cues during this play with his or her father. Since excitement of play is increased with their fathers, children are also given the opportunity to practice emotion regulation skills in a secure play environment (Parke, 1996). This play environment is only effective in the development of emotion regulation and peer relations when it is provided with boundaries that are communicated by the father during play. A father who does not communicate these boundaries may end up teaching the child that excessive aggressiveness and over stepping other boundaries is ok during play (Leidy, Schofield, \& Parke, 2013).

The negative effects of father absence and the positive effects of father involvement have both been discussed. Communicating these consequences (both negative and positive) is a key factor in helping fathers and mothers understand the importance of maintaining father involvement especially in the presence of economic hardship. In relation to this current study, it is also important to understand the mother's desire and perception of father involvement in order to understand how to communicate the importance of the father's involvement and help families struggling with hardships and stress that may be exaggerated by father absence.

\section{Father's Contribution to Low Income Mother's Parenting}

As discussed earlier, fathers have differing beliefs as to what makes a good father and the roles they take in their children's lives. In a similar way, mothers have their own ideas of what a father's role involves, but sometimes these two beliefs do not coincide with one another. When this happens there can be negative outcomes within the parental relationship or even the parentchild relationship. Mothers tend to have more control when it comes to parenting, which may make it difficult for a father who wants to be a part of his child's life but is in conflict with the mother of the child. 
Mothers tend to take on a more central role in the caregiving of their children (McBride et al., 2005). This puts a greater amount of parenting power in the mother's hands which allows her to dictate the role a father may play in his child's life. This maternal dictation of what a father can and cannot do while parenting his child is called maternal gatekeeping (McBride et al., 2005). Maternal gatekeeping allows the mother to shift tasks and roles of parenthood to help meet her expectations of what parenthood should be. Although mothers may see this as a good thing, it may act as a double edged sword. If mothers see their children's fathers as less competent, this may lead mothers to discourage fathers' caregiving activities. This lack of confidence could then lead to low parental self-efficacy and relationship satisfaction within fathers (Tremblay \& Pierce, 2011). The father may pull out of the parenting duties altogether, which will leave the mother with more caregiving responsibilities than she originally expected. This expectation violation may have a detrimental effect on the parental relationship or on the mother's well-being.

Researchers have found that if mother's expectations about parenting are unmet then it decreases relationship satisfaction and increases depression and other mental health symptoms (Biehl \& Mickelson, 2012; Goldberg \& Perry-Jenkins, 2004). Biehl and Mickelson (2012) looked at a middle class sample from Akron, $\mathrm{OH}$ and focused on expectations that were centered on how much play and child-care each parent expected to participate in and how much they expected their partner to participate in. As stated earlier, when mother's expectations were unmet (i.e., they did more caregiving than anticipated), they experienced a decrease in relationship satisfaction and repeated unmet expectations led to an increase in depressive symptoms. However, Goldberg and Perry-Jenkins (2004) found in a working class sample that not only do unmet expectations in mothers have a negative effect on mental health symptoms 
and relationship quality, but so do over-met expectations (i.e. father participates more in caregiving than the mothers expected). They believe this may be due to a more traditional ideology of motherhood (i.e. the mother should be the primary caregiver) or the mother needs to return to work despite her desire to stay home with her child (Goldberg \& Perry-Jenkins, 2004). The same can be said for fathers concerning over-met expectations for play. If the mother was more involved with play than the father originally expected, the father experienced a decrease in relationship satisfaction and a decrease in parenting self-efficacy. These findings show the significant role that expectations and father's actual actions play in mother's parenting, and the effect it may have on the mother's mental health and overall ability to parent. When both mothers and fathers have a similar view on paternal involvement, not only will mothers benefit but fathers will be more involved as well (Lamb \& Lewis, 2013).

Because of the reciprocal relationship of the mother and father in parenting, children are both directly and indirectly affected by their parents' relationship. The current study specifically looks at the parenting dyad (i.e. father's involvements influence on mother's perceptions of parenting), but it is important to mention that if the parenting dyad is functioning positively (i.e. mother's parenting perceptions are positively influenced by father involvement) then this could have a positive influence on the child. Most researchers have found results to this effect.

Choi (2010) found that in a low-income, urban sample, father parenting practices have an indirect positive effect on child outcomes through the mother. Paternal practices directly influence mother parenting practices which in turn directly affect child developmental outcomes (i.e. cognitive development, behavior problems). The study also found that non-resident, involved fathers do play an important role in the development of their children in an indirect way through the mother as well (Choi, 2010). Despite these encouraging findings, Choi (2010) found 
no statistically significant relationship between the mother/father relationship and maternal parenting. This is contradictory to findings from other researchers using similar samples that show a significant positive relationship between the mother/father relationship and maternal parenting (Davies, Sturge-Apple, \& Cummings, 2004; Jackson \& Scheines, 2005; Lamb \& Lewis, 2013); however, Choi (2010) does admit to using a maternal parenting measure that is different than what other researchers have used.

Bachman et al. (2012) also found in their research the importance of the mother/father relationship. Adolescents in urban, low-income families had less externalizing behaviors when their mothers had always been married, compared to single mothers and cohabitating mothers, regardless if the mother was married to the adolescent's biological father or a stepfather. The authors also found that there were fewer internalizing behaviors in low-income adolescents with mothers who had always been married compared to mothers who had always been cohabitating (Bachman et al., 2012). Married mothers reported more father involvement, more routine at home and less economic and parenting stress than single mothers and cohabitating mothers (Bachman et al., 2012).

Another thing to consider in terms of low-income parenting is the indirect effect fathers have on mother's parenting through his financial contribution. Greene and Moore (2000) found that, in a low-income sample, receiving financial support from the children's father was related to fewer behavioral problems and greater social and emotional adjustment in children. The financial support given allows the mother to provide the child a more secure and developmentally encouraging environment (Greene \& Moore, 2000). The authors argue that for fathers who are providing this support willingly and especially for those who are providing informal support this can be indicative of their desire to remain involved in their child's life and 
this could be the reason for the better child adjustment (Greene \& Moore, 2000). These findings reflect the importance of the stability of a father figure's involvement in the child and mother's life even through economic hardship. However, there have been other studies which have found that economic hardships create marital problems which in turn lead to less warmth from the father and ineffective parenting practices (Brody et al., 1994; Conger et al., 1990; Magnuson \& Duncan, 2005). If the father/mother dyad can remain strong through economic stress and hardships, the good quality of their relationship will have a positive effect on how they, both father and mother, parent their child (Lamb \& Lewis, 2013). This can in turn protect the child and family unit from the negative effects of poverty (e.g. negative parenting practices, internalizing and externalizing child behaviors, poor parental mental health outcomes). Presented in this literature review were specific ways in which fathers are important in the parenting process. In light of these findings and the apparent necessity of fathers in parenting within various samples, the current study will apply the concept of father importance to a rural, low-income Appalachian sample. This study specifically looks at father's influence on mother's perceptions of parenting.

\section{Current Study}

Appalachian region represents a vast array of groups and cultures. West Virginia, within Appalachia, however, has been characterized by poverty and single parent households. For example, between 2009 and 2013 there were 25,736 households with children under the age of 18 without a father present living in poverty in West Virginia compared to 14,365 married couples and 5,048 without a mother figure present living in poverty (US Census, 2014). This is congruent with Harper and McLanahan's (2004) assertion that father absence is more prevalent in more disadvantaged communities. Also, high poverty communities do not have access to 
similar resources as their wealthier counterparts which put them at an uncontrollable disadvantage (Gorski, 2013). Because of these risks associated with poverty, it is important to provide low-income families with as much information and support as possible in order to help them succeed.

The purpose of this study is to explore the influence of father involvement on mother's perceptions of parenting in a low-income Appalachian context. As discussed earlier, there is very little research done with an Appalachian sample, but based on previous research with lowincome environments, it is clear that economic hardships increase a family's susceptibility to negative outcomes (Brody et al., 1994; Conger \& Conger, 2002; Conger et al., 1992, 1993; Conger et al., 1990; Magnuson \& Duncan, 2005) and that father's involvement in the child's life and parenting can lead to better outcomes for both child and mother (Bachman et al., 2012; Davies, Sturge-Apple, \& Cummings, 2004; Greene \& Moore, 2000; Jackson \& Scheines, 2005; Lamb \& Lewis, 2013). Understanding if these research findings are consistent in an Appalachian context is important to not only broaden the scope of literature but more importantly it is needed to support and develop appropriate resources and understanding for the people of Appalachia. If father involvement has a positive correlation with mother's perceptions of parenting, this could be a good first step in starting to improve negative effects of impoverished conditions by finding ways to encourage father involvement in Appalachia. This may be done through providing important information about father's influence during prenatal visits or after the birth of the child in hospitals. Another possible way to encourage father involvement in a low-income area that may have limited resources is by educating teachers, counselors, social workers, etc. on father involvement and encouraging them to pass this information on to the parents they have influence over. 
When fathers are involved in their children's lives in a way similar to how Pleck (2010) and Fagan and Palkovitz (2011) define involvement (i.e. they are engaged and involved in observable ways) they increase the chances of positive outcomes for the whole family, especially in the instances of economic hardship. The FAAR model states that as a family goes through a crisis or a time of stress they will use their resources to try and adjust in order to maintain normalcy (Patterson, 1988). When a father is involved, he is added to a list of resources that can be used to battle the crisis or stress that has been introduced to the family, examples of this is found throughout research. Green and Moore (2000) discuss the positive effects of the father being financially supportive which lessons the economic stress on the mother. But not only is that important, but research has also found that when a father is involved there are less behavioral problems than if he were absent (DeBell, 2008; Harper \& McLanahan, 2004; Mendle et al., 2009). It is also important to note that fathers play an important role in teaching emotion regulation and peer relations through play (McDowell \& Park, 2009; Paquette, 2004; Parke, 1996; Parke \& O'Neil, 2000). With all of this in mind, two hypotheses will be tested in this study:

Hypothesis 1: As father involvement increases, mother's positive perceptions of parenting will increase.

Hypothesis 2: Mothers with children who have involved fathers will have more positive perceptions of parenting than those mothers whose children's fathers are present $(\mathrm{H} 2 \mathrm{a})$ or are absent $(\mathrm{H} 2 \mathrm{~b})$.

Mothers from low-income, rural areas of West Virginia were administered questionnaires that included questions about their previous perceptions of parenting, current perceptions of parenting and the involvement of their child's father in parenting. 


\section{Chapter III}

\section{Method}

\section{Participants}

Participants recruited were mothers with children three to five years old. All participants recruited were from West Virginia and qualified for state assistance (e.g., Supplemental Nutrition Assistance Program (SNAP), Women, Infants and Children (WIC), Continuing Care Retirement Community (CCRC)). The sample was made up of five Caucasian mothers who, with the exception of one daycare teacher, were stay-at-home mothers. Mothers were 22-40 years old with a mean age of 30, and fathers (as reported by the mothers) were 27-36 years old with a mean age of 32 . Two of the fathers were unemployed and the remaining worked full time. Both mothers and fathers had varying degrees of education ranging from a high school diploma to a doctoral degree. All fathers were living in the home during the birth of the child and were currently living in the home with the mother and child. Concerning the children, there were three males and two females and three four year olds and two three year olds.

\section{Procedure}

Following approval from West Virginia University’s Institutional Review Board, participants were recruited using two methods: 1) recruitment flyers and listserv postings and 2) on-site data collection. The recruitment flyers and listserv postings contained the contact number and email address of the researcher as well as the online link to the questionnaires. Hard copies were placed at various sites or handed out and electronic copies were posted on listservs and Facebook groups (i.e. yardsale groups and rumor mill groups). For those who preferred or did not have internet access they were able to use the contact information to contact the researcher in order to verify that they qualified to participate (i.e. they have a child three to five years old and 
qualify for public assistance). If the participants did qualify, the participant and the researcher arranged a time for them to get in contact over the phone and the researcher then administered the consent form and the questionnaires to the participant. The first name of the participant was recorded on the consent form and her child's first name was recorded on the questionnaire. If the participant did have internet access they were able to access the questionnaires via the link and take the questionnaire by themselves online.

In the case of on-site data collection, data was collected from various informational fairs for parents and children in Morgantown, WV. The researchers handed out flyers for prospective participants to take home and fill out the survey online or they were given the option to fill out the survey on site at the informational fair. If the participant wanted to fill out the survey on site, they were administered the consent form (Appendix A) and questionnaires (Appendix B, C, D). All participants of the study received a $\$ 10$ gift card and were entered to win one of five $\$ 100$ gift cards. The name of the participant was recorded on the consent form and each participant was assigned an identification number. The names were stored separately from the questionnaires and locked in an office to ensure confidentiality.

The presented study is a part of a larger study in which additional qualitative data will be collected from those who qualify in a $2^{\text {nd }}$ phase. For the purposes of this study, only the data from the quantitative questionnaires were used. The approval from West Virginia University's Institutional Review Board was obtained for this study as part of the larger study.

\section{Questionnaires}

The questionnaires were created using Qualtrics and include a demographic questionnaire (Appendix B, a current parenting questionnaire (Appendix C), and a current father involvement parenting questionnaire (Appendix D). The demographic questionnaire contains 32 questions 
which ask for information about the child (age, sex, ethnicity, etc.), qualification for public assistance, information about the mother (occupation, ethnicity, birthdate, etc.), information about the father (birthdate, education level, etc.), relationship status of father and mother, etc.

The current parenting questionnaire was adapted from the Child-Rearing practices Report Questionnaire (CRPR-Q; Rickel \& Biasatti, 1982). It uses a Likert scale of 1 to 6 (1 being never and 6 being always) and asks about how often the mother does or feels a certain way while parenting now. There are 14 statements which include "I encourage my child to talk about their troubles," I give praise when my child is good," "I scold and criticize to make my child improve," "I set strict well-established rules for my child," etc. The parenting perceptions measure was found to be reliable $(\alpha=.95)$.

The other questionnaire is the current father involvement questionnaire. It was adapted from the Inventory of Father Involvement (Hawkins, Bradford, Palkovitz, Christiansen, Day, \& Call, 2002). This questionnaire is a mother reported questionnaire which uses a Likert scale of 1-5 ( 1 is none, 3 is average, and 5 is a lot) to measure questions about the involvement of the father in parenting. There are six questions which include: "How much responsibility does the father take for raising the child?", "How much does the father help with financial and material support of the child?", "How much does the father's involvement make things easier for you or make you a better parent?", etc. This measure was also found to be reliable $(\alpha=.86)$

\section{Data Analysis}

After questionnaires were administered and reviewed, 48 potential questionnaires were collected and reviewed. Of those 48 , five were completed and qualified for the study. The data from these five questionnaires was then transposed in an Excel document and SPSS was used for 
data analysis. Hypothesis 1 was tested by correlation and hypothesis 2 was unable to be tested due to small data size. 


\section{Chapter IV}

\section{Results}

The first hypothesis was that as father involvement increases, mother's positive perceptions of parenting will increase. This was tested by examining the correlation between father involvement and mother's perceptions of parenting. No significant associations were found, $\mathrm{r}(5)=.55, \mathrm{p}>.05$. (Appendix $\mathrm{E})$

The second hypothesis was that mothers with children who have involved fathers will have more positive perceptions of parenting than those mothers whose children's fathers are present or are absent. However, there was not a large enough sample size to test this hypothesis. 


\section{Chapter V}

\section{Discussion}

This study considered how mother's perceptions of parenting may be influenced by the father's involvement in parenting. Based on the data collected from the limited number participants of this study, no significant findings were found for the first hypothesis (i.e. when father's involvement increases, mother's positive perceptions of parenting increases) and the second hypothesis could not be tested (i.e. mothers with children who have involved fathers will have more positive perceptions of parenting than those mothers whose children's fathers are present or are absent). Four of the five sets of data had similar reports of father involvement and mother's parenting perceptions. With this information no conclusions can be made about if father involvement is influencing mother's perceptions of parenting.

These non-significant findings are inconsistent with some previous research that has found that father involvement does have a positive influence on mothers parenting practices in general (Bachman et al., 2012; Conger \& Conger, 2002; Conger et al., 1990; Greene \& Moore, 2000). In fact, these non-significant findings are inconsistent with all literature presented previously in that no other studies had non-significant findings. The most likely reason for these non-significant findings could be the low number of participants of this study (i.e. five) which did not allow enough information to find any correlations between father involvement and mother's perceptions of parenting. However, another possibility could be that another factor is influencing mother's perceptions of parenting within this sample more so than father involvement is (e.g. economic status, employment status, quality of spousal relationship and other familial relationships, etc.) or that father involvement and mother's perceptions of parenting may not be correlated within this population. A possibility for the lack of correlation 
between father involvement and mother's parenting perceptions could be a high emphasis on kinship and community networks in this population (Newsome et al., 2008). An emphasis on these networks would encourage support and add to the resources available for the mother. However, more research needs to be done before any kinds of assumptions or conclusions can be made.

An interesting finding that should also be discussed is that the mean for CRPR in terms of warmth/nurturance in the current study's low-income sample is 3.77. Other studies that have used the CRPR in higher income samples have found the mean for warmth/nurturance to be higher (i.e. 4 or greater) (Lin \& Fu, 1990; Runions, Vitaro, Cross, Shaw, \& Hall, 2014). This is an important observation to point out and consider for future research. This could be indicative of greater economic stress having a negative effect on mother's parenting; however, it is also important to not assume that a lower report in warmth/nurturance is bad for these families. Less warmth and more strictness could be used as a source of protection in a high stress environment.

\section{Limitations and Future Research}

A significant limitation of this study is the small sample size. There were five questionnaires that were completed and met qualifications for this study. Due to the small sample size, it was not possible to come to any significant conclusions based on the data. Many recruiting strategies were attempted and 48 surveys were started, but only five surveys were completed. Possible reasons for the low participation rate could be a perceived lack of time to start or finish the questionnaires, or it could also be a fear of judgment of parenting practices. In the future it might be helpful to encourage participants to refer friends for studies with similar populations. This would encourage trust from potential participants. With additional recruitment methods, a more diverse population may be found. This area of Appalachia is 
predominately Caucasian but having a more diverse population in terms of mother occupation and presence of the father would add value to the findings by giving a broader picture of how mothers with differing experiences may influence the findings and also add information about absent fathers and how that may affect mother's parenting perceptions.

Another limitation could be that father involvement is reported by mothers and not fathers themselves. It is possible that the father would view his involvement differently than the mother would. In both cases there may be biases, but it would be worth considering in future research. In cases of an uninvolved father, it may be impossible to ask the father to complete a questionnaire. However, when a father is involved or even present and willing to complete a questionnaire, it may be beneficial to the research to look at how fathers report their own involvement and how that correlates with mother's perceptions of parenting.

Another possibility for future studies would be to add a qualitative aspect to the study. The larger study that this data was taken from does have a qualitative aspect to it, but it will not look at father involvement in the qualitative portion of the study. For future studies, qualitatively researching what aspects of fathering mothers perceive as positive involvement could help practitioners give specific advice to parents during opportunities for parenting education. Researchers would be able to provide information about specific actions (e.g. getting up in the morning with the children, bathing the kids, providing economic support, etc.) that mothers report as positive and practitioners can use that information to encourage positive co-parenting practices. Practitioners and community outreach members can also involve fathers more by developing programs based around the father and his children. For example, community programs could host a father-daughter dance, a father-child swim day, implement a father-child 
playgroup, etc. Facilitating activities that encourage interaction and involvement between father and child is key in getting fathers involved outside of the home.

\section{Conclusion}

Throughout previous research father involvement in parenting has been shown to be a significant positive influence on mothers and children (Cabrera et al., 2000; Flouri \& Buchanan, 2004; Nettle, 2008). In relation to low-income populations, the FAAR model suggests that with more resources families are able to withstand stress, including economic stress, in a more positive manner (Patterson, 1988). With the idea that fathers add to the list of resources and can be a positive part of the parenting process, the goal of this study was to test if more father involvement led to more positive perceptions of parenting for mothers in a low-income, Appalachian context. This would help fill in the gap in Appalachian literature and provide valuable information for practitioners who are working with families as they go through economic hard times. However, with only five participants no significant results were found and no conclusions can be made about the Appalachian father's influence on mother's perceptions of parenting. Despite the low sample size and the lack of significant findings, further studying this topic is still important to the Appalachian region. Gorski (2003) points out that impoverished areas tend to lack the resources that are available to wealthier areas and with the high rate of families living in poverty in West Virginia (US Census, 2014) providing this area's practitioners and leaders with as much information as possible and encouraging positive outreach to families is important. In the future, implementing different methods of data collection could help to ensure more conclusive findings. 


\section{References}

Bachman, H. J., Coley, R. L., \& Carrano, J. (2012). Low-income mothers' patterns of partnership instability and adolescents' socioemotional well-being. Journal of Family Psychology, 26(2), 263-273.

Batteau, A. (1979). Appalachia and the Concept of Culture: A Theory of Shared Misunderstandings. Appalachian Journal, 7(1/2), 9-31.

Biehl, S. N., \& Mickelson, K. D. (2012). First-time parents' expectations about the division of childcare and play. Journal of Family Psychology, 26(1), 36-45.

Billings, D., Blee, K., \& Swanson, L. (1986). Culture, Family, and Community in Preindustrial Appalachia. Appalachian Journal, 13(2), 154-170.

Brody, G.H., Stoneman, Z., Flor, D., McCrary, C., Hastings, L., \& Conyers, O. (1994). Financial Resources, Parent Psychological Functioning, Parent Co-Caregiving, and Early Adolescent Competence in Rural Two-Parent African-American Families. Child Development, 65, 590-605.

Bryan, D.M. (2013). To parent or provide? The effect of the provider role on low-income men's decisions about fatherhood and paternal engagement. Fathering, 11(1), 71-89.

Cabrera, N. J., Tamis-LeMonda, C. S., Bradley, R. H., Hofferth, S., \& Lamb, M. E. (2000). Fatherhood in the Twenty-First Century. Child Development, 71(1), 127.

Choi, J. (2010). Nonresident fathers' parenting, family processes, and children's development in urban, poor, single-mother families. Social Service Review, 84(4), 655-677.

Conger, R. D., \& Conger, K. J. (2002). Resilience in Midwestern Families: Selected Findings from the First Decade of a Prospective, Longitudinal Study. Journal Of Marriage \& Family, 64(2), 361-373. 
Conger, R.D., \& Conger, K.J. (2008). Understanding the Processes Through which Economic Hardship Influences Families and Children. In D.R. Crane, T.B. Heaton (Eds.), Handbook of Families and Poverty (pp. 64-78). Thousand Oaks, CA: Sage Publications.

Conger, R. D., Conger, K. J., Elder, Jr., G. H., Lorenz, F. O., Simons, R.L., \& Whitbeck, F. O. (1992). A family process model of economic hardship and adjustment of early adolescent boys. Child Development, 63(3), 526-540.

Conger, R. D., Conger, K. J., Elder, Jr., G. H., Lorenz, F. O., Simons, R. L., \& Whitbeck, L. B. (1993). Family Economic Stress and Adjustment of Early Adolescent Girls. Developmental Psychology, 29(2), 206-219.

Conger, R., Elder, G., Lorenz, F., Conger, K., Simons, H., Whitbeck, L., Huck, S., \& Melby, J. (1990). Linking economic hardship to marital quality and instability. Journal of Marriage and the Family, 52, 643-656.

Davies, P. T., Sturge-Apple, M. L., \& Cummings, E. M. (2004). Interdependencies among interparental discord and parenting practices: The role of adult vulnerability and relationship perturbations. Development And Psychopathology, 16(3), 773-797.

DeBell, M. (2008). Children Living Without Their Fathers: Population Estimates and Indicators of Educational Well-being. Social Indicators Research, 87(3), 427-443.

Downs, W.R. \& Rindels, B. (2004). Adulthood depression, anxiety, and trauma symptoms: A comparison of women with nonabusive, abusive, and absent father figures in childhood. Violence and Victims, 19(6), 659-671.

Fagan, J., \& Palkovitz, R. (2011). Coparenting and Relationship Quality Effects on Father Engagement: Variations by Residence, Romance. Journal Of Marriage And Family, 73(3), 637-653. 
Flouri, E., \& Buchanan, A. (2004). Eearly fathers' and mothers' involvement and child's later educational outcomes. British Journal of Educational Psychology, 74, 141-153.

Greene, A. D., \& Moore, K. A. (2000). Nonresident Father Involvement and Child Well-Being Among Young Children in Families on Welfare. Marriage \& Family Review, 29(2/3), 159-180.

Goldberg, A. E., \& Perry-Jenkins, M. (2004). Division of labor and working-class women's wellbeing across the transition to parenthood. Journal of Family Psychology, 18(1), 225-236.

Gorski, P.C. (2003). Reaching and Teaching Students in Poverty. New York: Teachers College Press.

Harper, C. C., \& McLanahan, S. S. (2004). Father Absence and Youth Incarceration. Journal of Research On Adolescence (Wiley-Blackwell), 14(3), 369-397.1

Hawkins, A.J., Bradford, K.P., Palkovitz, R., Christiansen, S.L., Day, R.D., \& Call, V.R.A. (2002). The inventory of father involvement: A pilot study of a new measure of father involvement. The Journal of Men's Studies, 10, 183-196.

Horning, A.J. (2002). Myth, Migration, and Material Culture: Archaeology and the Ulster Influence on Appalachia. Historical Archaeology, 36(4), 129-149.

Jackson, A., \& Scheines, R. (2005). Single mothers' self-efficacy, parenting in the home environment, and children's development in a two-wave study [corrected] [published erratum appears in SOC WORK RES 2005 Jun;29(2):86]. Social Work Research, 29(1), 7-20.

Juby, C., Downs, W., \& Rindels, B. (2014). Intimate partner violence victimization, maternal child maltreatment, and the mediating impact of changes in family structure. Child \& Adolescent Social Work Journal. 31(3), 237-249. 
Lamb, M. E., \& Lewis, C. (2013). Father-child relationships. In N. J. Cabrera, C. S. TamisLeMonda (Eds.), Handbook of father involvement: Multidisciplinary perspectives (2nd ed.) (pp. 119-134). New York, NY, US: Routledge/Taylor \& Francis Group.

Leidy, M.S., Schofield, T.J., \& Parke, R.D. (2013). Fathers' contributions to children's social development. In N.J. Cabrera, C.S. Tamis-LeMonda (Eds.), Handbook of father involvement: Multidisciplinary perspectives( $2^{\text {nd }}$ ed.) (pp. 151-167). New York, NY: Routledge/Taylor \& Francis Group.

Lin, C.C., \& Fu, V.R. (1990). A comparison of child-rearing practices among Chinese, immigrant Chinese, and Caucasian American parents. Child Development, 61(2), 429433.

Magnuson, K.A., \& Duncan, G.J. (2005). Parents in Poverty. In M.H. Bornstein (Ed.), Handbook of parenting: Volume 4 social conditions and applied parenting (pp. 95-121). Psychology Press.

McBride, B.A., Brown, G.L., Bost, K.K., Shin, N., Vaughn, B., \& Korth, B. (2005). Paternal identity, maternal gatekeeping, and father involvement. Family Relations, 54(2), 360372.

McDowell, D.J., \& Parke, R.D. (2009). Parental correlates of children's peer relations: An empirical test of a tripartite model. Developmental Psychology, 45, 224-235.

Mendle, J., Harden, K. P., Turkheimer, E., Van Hulle, C. A., D’Onofrio, B. M., Brooks-Gunn, J., Rodgers, J.L., Emery, R.E., \& Lahey, B. B. (2009). Associations between father absence and age of first sexual intercourse. Child Development, 80(5), 1463-1480.

Nettle, D. (2008). Why do som dads get more involved than others? Evidence from a large British cohort. Evolution and Human Behavior, 29, 416-423. 
Newsome, W.S., Bush, K.R., Hennon, C.B., Peterson, G.W., \& Wilson, S.M. (2008). Appalachian families and poverty: Historical issues and contemporary economic trends. In D.R. Crane, T.B. Heaton (Eds.), Handbook of Families and Poverty (pp. 104-115). Thousand Oaks, CA: Sage Publication.

Patterson, J. M. (1988). Families experiencing stress: I. The Family Adjustment and Adaptation Response Model: II. Applying the FAAR Model to health-related issues for intervention and research. Family Systems Medicine, 6(2), 202-237.

Paquette, D. (2004). Theorizing the Father-Child Relationship: Mechanisms and Developmental Outcomes. Human Development, 47(4), 193-219.

Parke, R.D. (1996). Socialization and Sociability. In R.D. Parke (Ed.), Fatherhood (The Developing Child) (pp. 119-155). Cambridge, MA: Harvard University Press.

Parke, R.D., \& O’Neil, R. (2000). The influence of significant others on learning about relationships: From family to friends. In R. Mills \& S. Duck (Eds.), The developmental psychology of personal relationships (pp. 15-17). London: Wiley.

Pleck, J. H. (2010). Paternal involvement: Revised conceptualization and theoretical linkages with child outcomes. In M. E. Lamb (Ed.), The role of the father in child development (5th ed.) (pp. 58-93). Hoboken, NJ, US: John Wiley \& Sons Inc.

Pougnet, E., Serbin, L. A., Stack, D. M., Ledingham, J. E., \& Schwartzman, A. E. (2012). The Intergenerational Continuity of Fathers' Absence in a Socioeconomically Disadvantaged Sample.Journal Of Marriage And Family, 74(3), 540-555.

Rickel, A.U., \& Biasatti, L.L. (1982). Modification of the block child rearing practices report. Journal of Clinical Psychology, 38, 129-134. 
Runions, K.C., Vitaro, F., Cross, D., Shaw, T., \& Hall, M. (2014). Teacher-child relationship, parenting, and growth in likelihood and severity of physical aggression in the early school years. Merrill-Palmer Quarterly: Journal of Developmental Psychology, 60(3), 274-301.

Tremblay, S., \& Pierce, T. (2011). Perceptions of fatherhood: Longitudinal reciprocal associations within the couple. Canadian Journal of Behavioural Science/Revue Canadienne Des Sciences Du Comportement, 43(2), 99-110.

United States Census, (2010). Households and Families: 2010 - State - Urban/Rural and Inside/Outside Metropolitan and Micropolitan Area [Data file]. Retrieved from http://www.census.gov

United States Census. (2014). Poverty Status in the Past 12 Months of Families by family type by presence of related children under 18 years of age of related children: West Virginia [Data file]. Retrieved from http://www.census.gov/easystats/ 
Appendix A

Consent Form

DATE:

TIME:

Data collector initials:

Parent Name (Last, First):

Mailing address:

Phone Number:

Email address:

You have been asked to participate in a study being conducted by Amy E. Root in the Department of Learning Sciences \& Human Development at West Virginia University with funding provided by the College of Education \& Human Services.

In the event you experience any side effects or injury related to this research, you should contact Amy E. Root at (304) 293-0380. If you have any questions, concerns, or complaints about this research, you can contact Amy E. Root at (304) 293-0380. For information regarding your child's rights as a research subject, to discuss problems, concerns, or suggestions related to the research, to obtain information or offer input about the research, contact the Office of Research Integrity and Compliance (304) 293-7073. In addition if you would like to discuss problems, concerns, have suggestions related to research, or would like to offer input about the research, contact the Office of Research Integrity and Compliance at 304-293-7073.

\section{Do you have any questions about who you can contact if you have concerns?}

\section{Did the participant understand? NOS}

The purpose of this study is to learn more about parenting in rural families. WVU expects to enroll approximately 100 mothers of preschool-aged children. This study involves answering questions about you and your family and your views on parenting your preschool-aged child. The first phase of the study will involve answering questions and should take about 20 minutes. It is important to note that you do not have to answer all the questions. You will receive a $\$ 10.00 \mathrm{gift}$ card for completing this portion of the study, even if you choose not to answer all questions; you will also be entered into a drawing to receive a $\$ 100.00$ gift card (one of five).

\section{Do you have any questions about the purpose of the study?}

Did the participant understand? YES NO

\section{Do you have any questions about taking part in the study?}

Did the participant understand? YES NO

Please note that data will be recorded either in aggregate or anonymously (i.e., your name will not be identified in any reporting of the results). I will record your answers on a computer that is password-protected and your name will not be 
entered. I will record down the name of you and your child's first name, but that information will be kept separate from your answers. This information will be kept on a password-protected computer in a locked office.

Please know that all your answers will be kept confidential and information collected from you today will be represented by a number (not your name). Any information about you that is obtained as a result of your participation in this research will be kept as confidential as legally possible. Your research records and test results, just like hospital records, may be subpoenaed by court order or may be inspected by federal regulatory authorities without your additional consent. In addition, there are certain instances where the researcher is legally required to give information to the appropriate authorities. These would include mandatory reporting of infectious diseases, mandatory reporting of information about behavior that is imminently dangerous to you or to others, such as suicide, child abuse, etc.

Do you have any questions about how we will keep the information you provide to us private and confidential?

Did the participant understand? YES NO

Participation in this study is voluntary. You are free to withdraw your consent to participate in this study at any time. Refusal to participate or withdrawal will involve no penalty to you.

Do you have any questions about your participation in the study?

Did the participant understand? YES NO

You may be invited to participate in an additional portion of this study. We expect to enroll 30 participants in the second interview. This additional interview, should you choose to participate, will take approximately $1-1.5$ hours and you will receive a $\$ 50.00$ gift card for your time, and an additional entry to receive one of five $\$ 100.00$ gift cards. The follow-up session will be done over the phone and will be audio recorded.

May we contact you at to participate in a follow-up? YES NO

Do you have any additional questions about the study? 
Appendix B

Demographic Questionnaire

ID \#

Date

Child's Age

Child's Sex (circle one):

MALE FEMALE

\section{SCREENING OUESTIONS}

Does $\leq<$ FIRST NAME OF CHILD $>>$ currently live with you ? YES NO

Do you qualify for SNAP/Food stamps? YES NO

Do you qualify for CCRC (subsidized child care)? YES NO

Do you qualify for WIC? YES NO

Which state and county do you currently reside?

\section{DEMOGRAPHICS}

Is your child biological? Adopted? Foster child?

Child's Ethnicity (circle one):

Hispanic or Latino

Not Hispanic or Latino

Child's Race (check one):

American Indian/Alaska Native

Asian

Black or African American

Native Hawaiian or Other Pacific Islander 

White or Caucasian
Bi- or Multi-racial (please specify):
Other (please specify):

\section{Mother's Age}

\section{Occupation}

\section{Mother's Ethnicity (circle one):}

Hispanic or Latino

Not Hispanic or Latino

\section{Mother's Race (check one):}

American Indian/Alaska Native

Asian

Black or African American

Native Hawaiian or Other Pacific Islander

White or Caucasian

Bi- or Multi-racial (please specify):

Other (please specify):

What the mother's employment status: Employed full-time

Employed part-time

Not employed outside of home

Retired

Unemployed

Other (specify)

Mother's education level:

Elementary School

High School

Vocational School

Some College

University Degree

Some Graduate School

Master's Degree

Doctoral Degree

Other (specify) 
Father's Age

Occupation

What the father's employment status: Employed full-time

Employed part-time

Not employed outside of home

Retired

Unemployed

Other (specify)

Father's education level:

Elementary School

High School

Vocational School

Some College

University Degree

Some Graduate School

Master's Degree

Doctoral Degree

Other (specify)

Did the biological father of the child reside with the biological mother when the child was born? YES NO

Does the biological father of the child currently reside with the biological mother?

Other children in the home? YES NO

If yes, ages: 
Appendix C

\section{PARENTING OUESTIONNAIRES - CURRENT}

For the next set of questions we'd like you to think about how you parent today. For this questionnaire we'd like you to tell us how often you do or feel certain things related to parenting today with . You'll tell me how often, again from 1 to 6 , with 1 being never and 6 being Almost Always. Again, the following statements represent matters of interest and concern to parents. Not all parents feel the same way about them. Some may apply to you and some may not. There are no right or wrong answers; we are interested in your perspective on parenting.

I Exhibit This Behavior:

$1=$ Never

2=Once in Awhile

$3=$ About Half of the Time

$4=$ Often

$5=$ Very Often

$6=$ Almost Always

I encourage my child to talk about their troubles.

I guide my child by punishment more than by reason.

I give praise when my child is good.

I show sympathy when my child is hurt or frustrated.

I punish by taking privileges away from my child with little if any explanation.

I scold and criticize to make my child improve.

I show patience with my child.

I have warm and intimate times together with my child.

When two children are fighting, I discipline the children first and ask questions later.

I scold or criticize when my child's behavior doesn't meet my expectation.

I show respect for my child's opinions by encouraging my child to express them.

I set strict well-established rules for my child.

I explain to my child how I feel about my child's good and bad behavior.

I use threats as punishment with little or no justification. 


\section{Appendix D}

\section{PARENTING OUESTIONNARIES - CURRENT FATHER INVOLVEMENT}

Next, we'd like to ask about 's father. The following items are measured on a 5-point Likert scale ranging from 1 (none) to 3 (average) to 5 (a lot).

1. How much responsibility does the father take for raising the child?

2. How much does the father help with financial and material support of the child?

3. How much does the father's involvement make things easier for you (the child's mother) or make you (the child's mother) a better parent?

4. How many hours per week does the father take care of the child?

5. How often does the father see or visit with the child?

6. How often does the child see or visit with the father's family? 
Appendix E

Means and Standard Deviations for the Variables

\begin{tabular}{lccccc}
\hline \hline Variable & $N$ & $M(S D) / \%$ & Median & Mode & Range \\
\hline \hline Father Involvement & 5 & $3.65(.38)$ & 4.00 & 4.00 & 1.43 \\
Mother's Perceptions & 5 & $3.77(.55)$ & 3.71 & $3.14^{\mathrm{a}}$ & 1.00 \\
& & & & & \\
\hline
\end{tabular}

a. Multiple modes exist. The smallest value is given 